\title{
Clonal amplification of Fasciola hepatica in Galba truncatula: within and between isolate variation of triclabendazole- susceptible and -resistant clones
}

\author{
Jane E. Hodgkinson ${ }^{1 *}$ (D, Krystyna Cwiklinski ${ }^{1,2}$, Nicola Beesley ${ }^{1}$, Catherine Hartley ${ }^{1}$, Katherine Allen ${ }^{1}$
} and Diana J. L. Williams ${ }^{1}$

\begin{abstract}
Background: Fasciola hepatica is of worldwide significance, impacting on the health, welfare and productivity of livestock and regarded by WHO as a re-emerging zoonosis. Triclabendazole (TCBZ), the drug of choice for controlling acute fasciolosis in livestock, is also the drug used to treat human infections. However TCBZ-resistance is now considered a major threat to the effective control of $F$. hepatica. It has yet to be demonstrated whether $F$. hepatica undergoes a genetic clonal expansion in the snail intermediate host, Galba truncatula, and to what extent amplification of genotypes within the snail facilitates accumulation of drug resistant parasites. Little is known about genotypic and phenotypic variation within and between F. hepatica isolates.

Results: Six clonal isolates of $F$. hepatica ( $3 \times$ triclabendazole-resistant, TCBZ-R and $3 \times$ triclabendazole-susceptible, TCBZ-S) were generated. Snails infected with one miracidium started to shed cercariae 42-56 days post-infection and shed repeatedly up to a maximum of 11 times. A maximum of 884 cercariae were shed by one clonally-infected snail (FhLivS1) at a single time point, with > 3000 clonal metacercariae shed over its lifetime. Following experimental infection all 12 sheep were FEC positive at the time of TCBZ treatment. Sheep infected with one of three putative TCBZ-S clones and treated with TCBZ had no parasites in the liver at post-mortem, whilst sheep each infected with putative TCBZ-R isolates had 35-165 adult fluke at post-mortem, despite TCBZ treatment. All six untreated control animals had between 15-127 parasites. A single multi-locus genotype was reported for every fluke from each of the six clonal isolates. Adult $F$. hepatica showed considerable variation in weight, ranging from 20-280 $\mathrm{mg}$, with variation in weight evident within and amongst clonal isolates.

Conclusions: A genetic clonal expansion occurs within G. truncatula, highlighting the potential for amplification of drug resistant genotypes of $F$. hepatica. Variation in the weight of parasites within and between clonal isolates and when comparing isolates that are either susceptible or resistant to TCBZ represent inherent variation in liver fluke and cannot be attributed to their resistance or susceptibility traits.
\end{abstract}

Keywords: Fasciola hepatica, Galba truncatula, Triclabendazole resistance, Clonal isolate, Isolate variation

\footnotetext{
* Correspondence: jhodgkin@liv.ac.uk

${ }^{1}$ Veterinary Parasitology, Dept Infection Biology, Institute of Infection and

Global Health, University of Liverpool, Liverpool L69 7ZJ, UK

Full list of author information is available at the end of the article
}

(c) The Author(s). 2018 Open Access This article is distributed under the terms of the Creative Commons Attribution 4.0 International License (http://creativecommons.org/licenses/by/4.0/), which permits unrestricted use, distribution, and reproduction in any medium, provided you give appropriate credit to the original author(s) and the source, provide a link to the Creative Commons license, and indicate if changes were made. The Creative Commons Public Domain Dedication waiver (http://creativecommons.org/publicdomain/zero/1.0/) applies to the data made available in this article, unless otherwise stated. 


\section{Background}

Fasciola hepatica is a trematode parasite of worldwide significance. A commonly diagnosed helminth parasite in sheep and cattle it is increasing in prevalence and spreading into new areas [1, 2] and is regarded by the WHO as a re-emerging zoonosis, with an estimated 17 million people at risk of infection [3]. It has a two-host life-cycle involving a mammalian definitive host, typically sheep and cattle, and a molluscan intermediate host, predominantly Galba truncatula in the UK and across western Europe. Following embryonation of $F$. hepatica eggs shed in the faeces of an infected host, the miracidia hatch and infect the snail, where parasite amplification occurs prior to shedding of multiple cercariae $\sim 6-8$ weeks post-infection. These cercariae encyst on vegetation as metacercariae; the infective stage that is subsequently ingested by the definitive host. On ingestion of metacercariae the newly excysted juvenile (NEJ) stage migrates through the liver and can cause disease known as acute fasciolosis, a significant cause of morbidity and mortality in livestock, particularly sheep. Temperature and rainfall are the principle determinants affecting the life-cycle and hence the prevalence and intensity of $F$. hepatica infection [2]. It is suggested that climate change is at least partly responsible for the increase in the prevalence of F. hepatica [4] and is thought to exacerbate the financial and welfare impact of fasciolosis on livestock production [5].

Triclabendazole (TCBZ), a key compound in the control of acute fasciolosis in livestock due to its efficacy against NEJ as early as two days post-infection [6], is also the drug of choice to treat human fasciolosis. The heavy reliance on TCBZ to treat sheep and cattle at frequent intervals has resulted in the emergence of TCBZ-resistance first in Australia and subsequently in many other countries [7-9]. It is now considered a major threat to the effective control of $F$. hepatica worldwide [10, 11]. The genetic and molecular basis of TCBZ resistance remains unknown. Linkage mapping for drug resistance has proved highly successful for protozoan parasites, for example malaria and Eimeria [12], and for trematodes such as Schistosoma mansoni $[13,14]$. These mapping exercises rely on access to a number of specific resources; a high quality genome assembly and linkage map [15] and the availability of clonal isolates. Significant advances have been made recently with publication of the first draft of the F. hepatica genome in 2015 [16] and work is underway to enhance its assembly. To date the majority of TCBZ resistance studies have been conducted on laboratory isolates, for example, the TCBZ-susceptible (TCBZ-S) Fairhurst and Cullompton isolates and TCBZ-resistant (TCBZ-R), Sligo and Oberon isolates [17, 18]; which were isolated from the field more than a decade ago $[19,20]$.
The need to routinely confirm the susceptibility of isolates used in drug resistance and drug development trials was highlighted recently [21]. At the genetic level, all currently available fluke isolates are either not characterised or at best are only partially genetically defined. A source of genotypically characterised clonal lines, phenotypically defined for their sensitivity to key drugs like TCBZ, is essential to the success of forward genetic approaches that have proved so successful in mapping drug resistance loci in other parasites $[14,21,22]$.

Here, we report the production of six clonal isolates by experimental infection of G. truncatula with a single miracidium derived from one of five field isolates and one laboratory maintained isolate of $F$. hepatica (Shrewsbury isolate, Ridgeway Research Ltd). Clonal isolates were phenotypically defined for their sensitivity to TCBZ by experimental infection in sheep and subsequent treatment with TCBZ at the recommended dose rate of $10 \mathrm{mg} / \mathrm{kg}$. Genotyping of each isolate was carried out using a F. hepatica microsatellite panel [23]. These neutral markers were used to confirm the capacity for genetically clonal amplification of $F$. hepatica within $G$. truncatula and provided a multilocus genotype (MLG) with which to uniquely identify each clonal isolate.

\section{Methods}

\section{Source of eggs for Fasciola hepatica clonal isolates}

Six clonal isolates of $F$. hepatica, $3 \times$ TCBZ-R and $3 \times$ TCBZ-S, were generated. For the TCBZ-R isolates, three field isolates of $F$. hepatica were sourced from naturally infected sheep with a history of TCBZ treatment: FhLivR1, Northwest England, UK; FhLivR2, South Wales, UK and FhLivR3, Northwest England, UK (a location distinct from FhLivR1). For the TCBZ-S isolates, two field isolates were sourced from naturally infected sheep not previously exposed to TCBZ; FhLivS2, Northwest England, UK and FhLivS3, Southwest England, UK. An additional isolate, FhLivS1, was sourced from cattle experimentally infected with the laboratory maintained TCBZ-S Shrewsbury isolate (Ridgeway Research Ltd, UK). Eggs were recovered from the gall bladder of infected sheep/purged from $F$. hepatica adult parasites at post-mortem (FhLivS1, FhLivR1 and FhLivR3) or isolated from faecal samples using a standard sedimentation method (FhLivS2, FhLivS3, FhLivR2).

\section{Maintenance and experimental infection of G. truncatula and production of $F$. hepatica metacercariae}

Galba truncatula snail stocks were maintained on pans of clay mud and fed on a diet of Oscillatoria spp. algae. Both the snails and algae were maintained at a controlled temperature of $22{ }^{\circ} \mathrm{C}$. For experimental infection of snails, $F$. hepatica eggs were embryonated at $27{ }^{\circ} \mathrm{C}$ in the dark for 14 days followed by exposure to a direct 
light source to stimulate hatching of miracidia. A single miracidium was co-incubated with an individual snail of approximately $4 \mathrm{~mm}$ in height in each well of a 48-well plate in $\sim 200 \mu \mathrm{l}$ of $\mathrm{H}_{2} \mathrm{O}+\sim 100 \mu \mathrm{l}$ algae and incubated for a minimum of $4 \mathrm{~h}$. Following infection, snails were maintained on mud pans and fed every 2-3 days. At 6 weeks post-infection (wpi), individual snails were sealed in visking tubing containing $\mathrm{H}_{2} \mathrm{O}$ and stimulated to shed cercariae by exposing snails to a drop in temperature to $12{ }^{\circ} \mathrm{C}$ for $30 \mathrm{~min}$ followed by a slow return to RT under a light source over a period of several hours. They were then left overnight to allow metacercariae to encyst on the visking tubing. Metacercariae were subsequently stored at $4{ }^{\circ} \mathrm{C}$. Individual snails were shed repeatedly and metacercariae from each individual snail were pooled prior to infection of sheep.

\section{Experimental infection of sheep and recovery of adult parasites at post-mortem}

Typically, experimental infections were carried out using lambs $\sim 3$ months of age that had no access to pasture. Animals were housed in group conditions in an indoor facility and fed on growing sheep concentrate pellet with hay and water provided ad libitum. Lambs were inspected at least daily for the duration of the sampling period. Prior to infection lambs were confirmed free of F. hepatica infection by antibody detection ELISA using F. hepatica ES antigens ELISA [24] and faecal egg count (FEC) using a standard sedimentation technique. Infections were performed by oral administration of metacercariae to two sheep per isolate using a dose of $\sim 200$ clonal metacercariae per sheep. The viability of metacercariae was assessed prior to infection by visualising flame cells, if no flame cells were seen the metacercariae were considered to be non-viable. One sheep from each pair was treated with TCBZ at the recommended dose rate of $10 \mathrm{mg} / \mathrm{kg}$, whilst the other sheep remained as an untreated control. All sheep were euthanized 10 days post-TCBZ treatment (time of euthanasia was different for each clone and ranged from 17-24 wpi). Infection status was monitored weekly by ELISA from four weeks prior to infection until post-mortem or by FEC from, pre-infection and then from eight wpi until necropsy. At post-mortem liver flukes were manually recovered directly by dissection from the bile ducts or following slicing of the liver and incubation in PBS for $2 \mathrm{~h}$ at $37^{\circ} \mathrm{C}$. Eggs were harvested from adult parasites purged by incubation in 1-2 ml of Dulbecco's Modified Eagle's Media (DMEM; Sigma-Aldrich, Dorset, UK) for a minimum of $2 \mathrm{~h}$ at $37^{\circ} \mathrm{C}$. The parasites were then removed from the culture medium, whole parasites were weighed and all fluke material (including partial fluke) was snap frozen in liquid nitrogen. Purged eggs were stored at $4{ }^{\circ} \mathrm{C}$; batches were periodically embryonated as described above and passaged through snails and sheep to maintain clonal lines.

\section{Genotyping of clonal isolates}

The entire adult fluke or a section of adult fluke near the anterior sucker, representing $20 \mathrm{mg}$ of tissue was used for DNA extraction. Genomic DNA extraction was carried out using the DNeasy Blood and Tissue Kit (for $20 \mathrm{mg}$ tissue) or Genomic tip 100G (for whole adult fluke) (both Qiagen, Manchester, UK), according to the manufacturer's instructions. For the majority of samples this was followed by an ethanol precipitation and re-suspension of DNA in a volume of $60 \mu \mathrm{TE}$ ( $\mathrm{pH}$ 8.0). All DNA concentrations were calculated using the Quant-iT $^{\mathrm{TM}}$ PicoGreen $^{\circ}$ dsDNA assay kit (Life Technologies, Thermo Fisher Scientific, Rugby, UK). Microsatellite PCR and sequencing was essentially carried out as described [23, 25] by employing the multiplex protocol using the Type-it Microsatellite PCR kit (Qiagen, UK) according to the manufacturer's instructions and 1 $\mu \mathrm{l}(10 \mathrm{ng})$ of adult genomic DNA template. PCR products were analysed by agarose gel electrophoresis (2\% gel) using $\mathrm{SYBR}^{\circ}$ Safe DNA stain (Life Technologies). If a positive result was obtained by gel electrophoresis, the PCR products were diluted 25 or 50 fold and $1 \mu \mathrm{l}$ of this dilution multiplexed in Hi-Di Formamide (8.8 $\mu \mathrm{l}$; Life Technologies) with GeneScan LIZ500 size standards $(0.2$ $\mu$ l; Life Technologies), prior to sequencing using a 3100 Genetic Analyzer capillary electrophoresis system (Life Technologies) and Peak Scanner v1.0 software.

\section{Results}

\section{Clonal amplification of Fasciola hepatica in Galba truncatula}

Five clonal isolates were derived using populations of eggs from naturally infected UK sheep flocks, from one of several geographical locations (Table 1). Low rates of infection in snails and high mortality of infected snails commonly occurs in experimental systems, hence, to generate the six clonal isolates multiple individual snail:miracidium infections were set up for each population; with a total of between 30-40 snails clonally infected per isolate. Infected snails were first detected to be shedding cercariae from 42-56 days post-infection (dpi). Although some snails shed once and died, the majority (75-89.6\%) continued to shed cercariae multiple times up to a maximum of 11 times. A snail infected with one miracidium can generate large numbers of cercariae, with one snail producing $>3000$ clonal metacercariae (Table 2). Infected snails shed vastly different numbers of cercariae over their lifetime with a maximum of 884 cercariae shed by any one snail at a given time-point (data not shown). The snail shedding the 
Table 1 Details of field samples used to generate six Fasciola hepatica clonal isolates

\begin{tabular}{|c|c|c|c|}
\hline $\begin{array}{l}\text { Clonal } \\
\text { isolate }\end{array}$ & Origin of $F$. hepatica eggs & $\begin{array}{l}\text { Geographical location } \\
\text { of farm }\end{array}$ & History of TCBZ exposure \\
\hline FhLivR1 & $\begin{array}{l}\text { Purged from adult parasites recovered at PM } \\
\text { (AHVLA) }\end{array}$ & North West England & $\begin{array}{l}\text { Frequent use of TCBZ, treated with TCBZ } 28 \text { days prior to } \\
\text { PM and } 2 \text { days prior to PM. Sheep died } 2 \text { days post-treatment }\end{array}$ \\
\hline FhLivR2 & $\begin{array}{l}\text { Isolated from faecal sample taken } 21 \text { days post-TCBZ } \\
\text { treatment }\end{array}$ & South Wales & $\begin{array}{l}\text { Population of } F \text {. hepatica showing } 98.2 \% \text { reduction based } \\
\text { on FECRT }^{a}\end{array}$ \\
\hline FhLivR3 & $\begin{array}{l}\text { Purged from adult parasites recovered at PM } \\
\text { (AHVLA) }\end{array}$ & $\begin{array}{l}\text { North West England } \\
\text { (not same farm as R1) }\end{array}$ & $\begin{array}{l}\text { History of TCBZ treatment failure on farm, last exposed to } \\
\text { TCBZ } 4 \text { months prior to PM }\end{array}$ \\
\hline FhLivS1 & $\begin{array}{l}\text { Shrewsbury laboratory isolate, commercially available } \\
\text { TCBZ susceptible population (Ridgeway Research Ltd, } \\
\text { UK) }\end{array}$ & $\begin{array}{l}\text { Isolated } 2006 \text { from } \\
\text { West England }\end{array}$ & $\begin{array}{l}\text { Population of F. hepatica showing TCBZ efficacy of } 97 \% \\
\text { in sheep }(n=9) \text {, Ridgeway Research Ltd (pers. comm.) }\end{array}$ \\
\hline FhLivS2 & $\begin{array}{l}\text { Isolated from faecal samples from organic sheep } \\
\text { farm }\end{array}$ & $\begin{array}{l}\text { North West England } \\
\text { (not same farm as R1 } \\
\text { or R3) }\end{array}$ & None \\
\hline FhLivS3 & $\begin{array}{l}\text { Isolated from faecal samples from organic sheep } \\
\text { farm }\end{array}$ & South West England & $\begin{array}{l}\text { Population of } F \text {. hepatica showing TCBZ efficacy of } 97.2 \% \\
\text { in sheep ( } n=12 \text {, data not shown) }\end{array}$ \\
\hline
\end{tabular}

${ }^{a}$ TCBZ-S based on criteria for faecal egg count reduction test (FECRT) [45]

${ }^{\mathrm{b}} \mathrm{TCBZ} \%$ efficacy defined based on critical test performed at 10 days after treatment and using the following calculation: \% efficacy = (mean of $F$. hepatica in control group - mean of $F$. hepatica in treated group/ mean of $F$. hepatica in control group) $\times 100$ [46]

Abbreviations: PM post-mortem, AHVLA/APHA Animal Health Veterinary Laboratory Agency/Animal and Plant Health Agency, TCBZ triclabendazole

largest number of cercariae was selected from each population and a subset of $\sim 400$ metacercariae derived from this clonally-infected snail was used to infect the two sheep for each clonal isolate $(\sim 200$ metacercariae per sheep). A single MLG was reported for every fluke from each of the six isolates (Table 4), uniquely identifying each clone. The presence of fluke of just a single genotype in each animal (or pair of animals infected with metacercariae derived from the same snail) confirmed a genetic clonal expansion had occurred in the snail and a clonal infection was established in the definitive host.

\section{Phenotyping of TCBZ-susceptible and TCBZ-resistant clonal isolates of Fasciola hepatica}

All three populations from which TCBZ-R clonal isolates were generated, were from cases referred by the farmer to the Veterinary Investigation Centre, Camarthen, Wales, UK (AHVLA, now called the Animal and Plant Health Agency, APHA); they were cases of suspected TCBZ resistance, due to therapeutic drug failure or death of sheep post-TCBZ treatment.

Prior to experimental infection all animals recorded negative FEC values and for those animals tested by ELISA (FhLivS1-S3) low percent positivity (PP) values

Table 2 Experimental infection of sheep for production of Fasciola hepatica clonal isolates

\begin{tabular}{|c|c|c|c|c|}
\hline $\begin{array}{l}\text { Clonal } \\
\text { isolate }\end{array}$ & $\begin{array}{l}\text { Total no. of cercariae shed by a single snail used to } \\
\text { derive clonal infections }\end{array}$ & $\begin{array}{l}\text { No. of metacercariae used for } \\
\text { infection }\end{array}$ & $\begin{array}{l}\text { Timepoint of PM } \\
\text { (wpi) }\end{array}$ & $\begin{array}{l}\text { No. of adult flukes } \\
\text { recovered at PM }\end{array}$ \\
\hline \multirow[t]{2}{*}{ FhLivR1 } & 931 & 150 & 18 & 70 \\
\hline & & 220 & 18 & $165(T)$ \\
\hline \multirow[t]{2}{*}{ FhLivR2 } & 553 & 193 & 18 & 31 \\
\hline & & 200 & 18 & $48(T)$ \\
\hline FhLivR3 & 812 & 256 & 18 & $35(\mathrm{~T})$ \\
\hline \multirow[t]{2}{*}{ FhLivS1 } & 3200 & 209 & 19 & 15 \\
\hline & & 224 & 19 & $0(\mathrm{~T})$ \\
\hline \multirow[t]{2}{*}{ FhLivS2 } & $>417^{b}$ & 215 & 24 & 113 \\
\hline & & 202 & 24 & $0(T)$ \\
\hline \multirow[t]{2}{*}{ FhLivS3 } & 1166 & 200 & 17 & 127 \\
\hline & & 200 & 17 & $0(T)$ \\
\hline
\end{tabular}

${ }^{\mathrm{a}}$ Two sheep were infected for each isolate and the dose of metacercariae given to each sheep is shown. Patency of infection was confirmed by faecal egg count and one sheep from each pair was treated with $10 \mathrm{mg} / \mathrm{kg}$ triclabendazole (T) 10 days prior to post-mortem (PM) with the exception of FhLivR3 where one sheep had to be euthanized during the course of the experiment. The number of adult flukes recovered from each sheep at PM is shown

${ }^{\mathrm{b}}$ Actual number not calculated

Abbreviations: wpi weeks post infection, PM post-mortem 
were recorded (0.2-6.5). A single dose of between 150256 metacercariae from a single snail exposed to one miracidia was administered to two animals (see Table 2). All animals were seropositive by 4 wpi (ELISA PP values ranged from 18.3-54.4) and were FEC positive by 10 wpi and eggs were consistently shed by all sheep until the day of treatment. The sheep recording the highest egg count was treated with TCBZ at $10 \mathrm{mg} / \mathrm{kg}$ whilst the other remained untreated (Table 3). All 12 sheep were FEC positive on the day of treatment (Table 3) consistent with the presence of egg producing adult parasites at the time of TCBZ treatment. Sheep infected with FhLivS1, S2 or S3 and treated with TCBZ had no adult liver fluke present at post-mortem, whilst TCBZ treated sheep infected with FhLivR1, R2 or R3 had fluke burdens ranging from 35-165 (Tables 3, 4). All six untreated control animals had liver fluke burdens with between 15-127 parasites per sheep (Table 2). This confirmed the resistant or susceptible phenotype of each isolate. The adult $F$. hepatica from each isolate showed considerable variation in the size of fluke both within and between clonal isolates, although it was not practical to measure the size of individual adult fluke. This was reflected in their weight; the larger the fluke the greater the weight. A minimum weight of $20 \mathrm{mg}$ (FhLivR1 isolate) and a maximum weight of $280 \mathrm{mg}$ (FhLivS3) was found. This variation was evident not only between clonal isolates but within each clonal isolate (Table 4).

\section{Genotyping of TCBZ-susceptible and TCBZ-resistant clonal isolates of Fasciola hepatica}

A high level of genetic differentiation was observed between isolates. The MLG for each isolate was distinct and a number of alleles were unique to each isolate, in particular loci Fh_2, Fh_4, Fh_5, Fh_6 and Fh_11 were represented by a different genotype for each isolate (Table 5).

\section{Discussion}

\section{Clonal isolates allow us to better understand Fasciola hepatica biology}

To date, no study has analysed $F$. hepatica parasites at the molecular level following their expansion within the snail intermediate host. The presence of multiple adult parasites of the same MLG, within a host exposed to metacercariae from a single snail infected with just one miracidium, is consistent with the clonal amplification of F. hepatica within G. truncatula. Studies on closely related trematodes, including Clonorchis sinensis, Opisthorchis viverrini and Schistosoma spp., have used molecular tools to demonstrate a genetic clonal amplification occurs within the snail intermediate host and have shown that mitotic recombination events can occur [26-28]; however, based on our analysis here there is no evidence to support mitotic recombination in $F$. hepatica.

It is difficult to compare published studies of snail infections with $F$. hepatica, given that husbandry and diet can affect cercarial output [29,30], but the experimental infection of snails performed here adds valuable insights into the capacity of snails to shed cercariae. The time from when snails were exposed to miracidia to the first observation of cercarial shedding is similar to previous studies [31-33]. However, the period of cercarial shedding by experimentally infected snails exceeds that reported elsewhere [31-34], but is similar to that of Hodasi et al. [35], where snails were fed the same diet (Oscillatoria spp.). The mean number of metacercariae produced by snails infected with a single miracidium has been reported as 114.9 (SD: 80.3) [32], which is lower than observed with our snails, probably due to the extended period over which our infected snails shed cercariae. As with other studies we observed that some snails are 'super-shedders' producing thousands of metacercariae [35].

Table 3 Faecal egg count and adult parasite burden at post-mortem for six Fasciola hepatica clonal isolates. Two sheep were infected for each clonal isolate, patency of infection was confirmed by faecal egg count (FEC), expressed as eggs per gram (epg). One sheep from each pair was treated with $10 \mathrm{mg} / \mathrm{kg}$ triclabendazole, the other sheep was left untreated. After 10 days all sheep were euthanised and adult liver fluke were enumerated post-mortem

\begin{tabular}{|c|c|c|c|c|}
\hline \multirow{2}{*}{$\begin{array}{l}\text { Clonal } \\
\text { isolate }\end{array}$} & \multicolumn{2}{|c|}{ FEC (epg) on day of treatment } & \multicolumn{2}{|c|}{ Number of adult liver flukes present post-mortem } \\
\hline & $\overline{\mathrm{TCBZ}+}$ & TCBZ- & $\overline{\mathrm{TCBZ}+}$ & TCBZ- \\
\hline FhLivR1 & 381 & 137 & 165 & 70 \\
\hline FhLivR2 & 324 & 50 & 48 & 31 \\
\hline FhLivR3 $^{a}$ & 186 & - & 35 & - \\
\hline FhLivS1 & 6 & 2 & 0 & 15 \\
\hline FhLivS2 & 146 & 57 & 0 & 127 \\
\hline FhLivS3 & 89 & 73 & 0 & 113 \\
\hline
\end{tabular}

${ }^{\mathrm{a}}$ FhLivR3, one sheep (TCBZ-) had to be euthanized for non-fluke related illness during the course of the experiment

Abbreviations: epg eggs per gram, FEC faecal egg count; TCBZ+, treatment with $10 \mathrm{mg} / \mathrm{kg}$ triclabendazole; TCBZ-, no treatment with $10 \mathrm{mg} / \mathrm{kg}$ triclabendazole 
Table 4 Phenotypic and genotypic characteristics of Fasciola hepatica clonal isolates

\begin{tabular}{|c|c|c|c|c|c|c|}
\hline & $\begin{array}{l}\text { No. of whole adult flukes } \\
\text { recovered at PM }\end{array}$ & $\begin{array}{l}\text { Mean weight of adult } \\
\text { flukes } \pm \mathrm{SD}(\mathrm{mg})\end{array}$ & $\begin{array}{l}\text { Median weight of } \\
\text { adult flukes (mg) }\end{array}$ & $\begin{array}{l}\text { Range of weights recorded } \\
\text { for adult flukes }(\mathrm{mg})\end{array}$ & $\begin{array}{l}\text { No. of adult } \\
\text { flukes genotyped }\end{array}$ & $\begin{array}{l}\text { No. of MLC } \\
\text { observed }\end{array}$ \\
\hline \multirow[t]{2}{*}{ FhLivR1 } & 70 & $108 \pm 22$ & 110 & $30-150$ & 70 & $1^{a}$ \\
\hline & $165(\mathrm{~T})$ & $83 \pm 28$ & 80 & $20-160$ & 165 & $1^{\mathrm{a}}$ \\
\hline \multirow[t]{2}{*}{ FhLivR2 } & 31 & $86 \pm 16.00$ & 90 & 50-130 & 31 & $1^{\mathrm{b}}$ \\
\hline & $48(T)$ & $98 \pm 20$ & 100 & $60-140$ & 48 & $1^{\mathrm{b}}$ \\
\hline FhLivR3 & $35(\mathrm{~T})$ & $102 \pm 30$ & 110 & $40-160$ & 35 & 1 \\
\hline \multirow[t]{2}{*}{ FhLivS1 } & 15 & $177 \pm 27$ & 180 & $90-210$ & 15 & 1 \\
\hline & $0(\mathrm{~T})$ & - & - & - & - & - \\
\hline \multirow[t]{2}{*}{ FhLivS2 } & $105^{c}$ & $148 \pm 25$ & 150 & $80-230$ & 110 & 1 \\
\hline & $0(\mathrm{~T})$ & - & - & - & - & - \\
\hline \multirow[t]{2}{*}{ FhLivS3 } & $112^{d}$ & $129 \pm 22$ & 130 & $80-280$ & 126 & 1 \\
\hline & $0(T)$ & - & - & - & - & - \\
\hline
\end{tabular}

\footnotetext{
${ }^{\text {a }}$ Same genotype in both animals

bame genotype in both animals

cPlus an additional 8 partial parasites

dPlus an additional 15 partial parasites

Abbreviations: FhLiv clonal isolate of Fasciola, $R$ resistant to triclabendazole, $S$ susceptible to triclabendazole, $(T)$ treated with $10 \mathrm{mg} / \mathrm{kg}$ triclabendazole 10 days prior to PM, PM post-mortem, MLG multilocus genotype based on a panel of 15 microsatellite markers
}

Gene flow is driven by multiplication and recombination events in the intermediate and definitive hosts, respectively. The genetic clonal expansion of $F$. hepatica in snails has the potential to reduce diversity of $F$. hepatica in the definitive host, particularly when the typical prevalence of infection in snails in the field is low $(\sim 5 \%)$ [36-38]. However, it has been shown that, in naturally infected sheep and cattle, F. hepatica exists as a panmictic population with high levels of diversity in populations infecting the definitive host [25]. It is not known to what extent $F$. hepatica undergoes self and cross-fertilisation and how this might influence gene flow, or whether $F$. hepatica undergoes multiple mating events. Previously, we have shown that the selfing rate of adult liver fluke infection in the definitive host is no higher than 2\% [25], which supports the current hypothesis that cross-fertilization predominates. In future, these clonal isolates, each identifiable with a unique MLG, constitute a valuable resource with which to explore gene flow and reproductive biology of the liver fluke life-cycle stages in vivo. Each of the six isolates can be tracked through infection in the snail and definitive host. Progeny (eggs and metacercariae) derived from mating between two parasite isolates, each with a distinct MLG, can be genotyped to identify if cross- or self-fertilization predominates in the definitive host and explore parasite mating behaviour.

\section{Variation within and between clonal isolates of Fasciola hepatica}

The fact that each clonal isolate, irrespective of drug resistance status, has a unique and distinct genetic profile is not surprising given previous work on whole-genome sequence variation [16]. What is of particular interest here is phenotypic variation within a clonal isolate. In naturally infected hosts mature, adult fluke differ considerably in weight, ranging from 40-280 mg, mean $130 \pm$ $4.36 \mathrm{mg}$ (of 205 liver fluke sampled from 26 sheep livers, data not shown). The impact of the host environment on parasite development, size and intestinal position has

Table 5 Unique multilocus genotypes for each of the six clonal isolates

\begin{tabular}{|c|c|c|c|c|c|c|c|c|c|c|c|c|c|c|c|}
\hline \multirow[b]{2}{*}{ Clonal isolate } & \multicolumn{15}{|l|}{ Locus $^{a}$} \\
\hline & $\overline{F h \_1}$ & $\mathrm{Fh} \_2^{\mathrm{b}}$ & Fh_3 & Fh_4 ${ }^{b}$ & $\mathrm{Fh} \_5^{\mathrm{b}}$ & Fh_6 ${ }^{b}$ & Fh_7 & Fh_8 & Fh_9 & Fh_10 & Fh_1 $11^{b}$ & Fh_12 & Fh_13 & Fh_14 & Fh_15 \\
\hline FhLivR1 & $08 / 10$ & $08 / 47$ & 07/08 & $18 / 20$ & $31 / 31$ & $33 / 36$ & $13 / 13$ & $11 / 16$ & 07/07 & 09/11 & 08/08 & $07 / 10$ & $08 / 11$ & $11 / 19$ & $14 / 14$ \\
\hline FhLivR2 & 08/08 & $08 / 45$ & 08/08 & $16 / 18$ & $24 / 24$ & $14 / 33$ & $11 / 11$ & $11 / 16$ & 06/07 & 09/15 & $07 / 14$ & $10 / 15$ & $08 / 11$ & $17 / 18$ & $09 / 14$ \\
\hline FhLivR3 & $11 / 11$ & $14 / 19$ & 07/08 & $16 / 20$ & $27 / 32$ & $30 / 32$ & $11 / 12$ & $12 / 12$ & 07/07 & 09/11 & $11 / 12$ & $15 / 16$ & 08/08 & $18 / 18$ & $09 / 14$ \\
\hline FhLivS1 & 08/08 & $18 / 19$ & 07/09 & $18 / 23$ & $24 / 32$ & $31 / 33$ & $12 / 12$ & $14 / 14$ & 06/07 & $10 / 16$ & $12 / 15$ & $10 / 10$ & 08/08 & 08/08 & $09 / 14$ \\
\hline FhLivS2 & 06/06 & 08/08 & 07/08 & $14 / 20$ & $27 / 31$ & $14 / 16$ & $12 / 12$ & $11 / 19$ & 06/07 & $06 / 11$ & $08 / 15$ & $10 / 10$ & $08 / 16$ & $17 / 19$ & $14 / 14$ \\
\hline FhLivS3 & $10 / 16$ & $14 / 15$ & 07/08 & $16 / 19$ & $27 / 30$ & $16 / 29$ & $13 / 13$ & $12 / 12$ & 07/07 & $11 / 14$ & $13 / 13$ & $05 / 10$ & $08 / 11$ & 08/08 & $09 / 14$ \\
\hline
\end{tabular}

${ }^{a}$ Alleles are identified by the number of microsatellite repeats. The two alleles of each genotype are separated by a /

${ }^{b}$ Loci where unique genotypes were recorded for each isolate 
been demonstrated for the parasitic nematode Strongyloides ratti [39]. This study has shown that clonal liver fluke, with identical MLG, can differ greatly in their weight (Table 4). This reveals how much the host environment influences the growth of parasites in the liver; for example, there is the potential for significant variation in the time taken to excyst, to exit the intestine and to enter liver tissue and migrate to the bile ducts. This variation is important, because size, along with specific morphological characteristics, is often used as a means of species-specific identification for Fasciola spp. [40]. Any/all of these variables could also influence the sizes of worms recorded. Regardless of what factors influence phenotypic variation, such variation is an important consideration when comparing isolates. For example, here it is not possible to attribute differences between isolates to resistance or susceptibility to TCBZ, because variation is apparent even when comparing two different isolates susceptible (or resistant) to TCBZ. This highlights that drug resistance studies on highly heterogeneous populations need to distinguish between the impact of standing genetic variation and that of genetic mutations responsible for conferring resistance traits. It is worth noting that a mutation in a PGP gene in a small number of TCBZ-resistant liver fluke in Northern Ireland [41] was not detected in a larger number of drug resistant fluke in Australia [42].

\section{Clonal isolates will advance our understanding of drug resistance in Fasciola hepatica}

A lack of understanding of the specific mechanisms involved in drug resistance in $F$. hepatica raises several important questions about the origins, heritability and spread of drug resistance alleles in liver fluke populations. The clonal isolates reported here allow, for the first time, genetic crossing experiments between TCBZ-S and TCBZ-R isolates and supports subsequent genome mapping approaches that are crucial to addressing these complex questions in future [21, 43, 44]. A lack of population structure and high gene flow in F. hepatica populations has revealed that TCBZ resistance has the potential to spread rapidly [36]. The capacity for snails infected with a single miracidium to shed large numbers of clonal metacercariae raises the possibility for aggregation of resistant genotypes on pasture which in turn may lead to infection of the definitive host with large numbers of drug-resistant parasites [25]. Thus, the clonal amplification of $F$. hepatica genotypes within G. truncatula demonstrated here highlights the potential for drug resistance alleles to accumulate rapidly within liver fluke populations.

Importantly, at a practical level our work provides valuable insights into interpretation of drug efficacy studies given the genetic diversity inherent in liver fluke populations. In the case of FhLivS1 and FhLivS3, critical tests using the population of parasites from which these drug sensitive clonal isolates were derived, showed a TCBZ efficacy of $97 \%$ (Table 1). This means that even in highly TCBZ susceptible populations a proportion of live, egg producing adult parasites survive and are retained in the liver post-treatment. This is in contrast to our observations here with clonal susceptible parasites where only one genotype is present and complete removal of parasites was seen post-TCBZ treatment (Table 2). It is not known whether the parasites that survive treatment are TCBZ-susceptible parasites or if they represent drug-resistant parasites within a population where TCBZ resistance alleles are at low frequency and where TCBZ-resistance is emerging. It is interesting to note that the TCBZ-resistant isolate FhLivR2, was derived from a population of parasites that, based on rigorous faecal egg count reduction test (FECRT) evaluation, was designated as TCBZ-susceptible [43]. This highlights the complexities of interpreting the FECRT and identifies the need for sensitive, molecular-based tests to determine the emergence of drug resistance in the field. Clonal isolates, such as those reported here will significantly enhance our ability to map drug resistance markers by integrating genetic crossing experiments with genome-wide bioinformatics approaches [20].

\section{Conclusions}

A genetic clonal expansion occurs within G. truncatula, highlighting the potential for amplification of drug resistant genotypes of $F$. hepatica. Variation in the weight of parasites within and between clonal isolates and when comparing isolates that are either susceptible or resistant to TCBZ represents inherent variation in liver fluke and cannot be attributed to their resistance or susceptibility traits. Clonal isolates will facilitate genetic mapping of drug resistance markers.

\section{Abbreviations \\ AHVLA: Animal Health Veterinary Laboratory Agency; APHA: Animal and Plant Health Agency; ELISA: Enzyme-linked immunosorbent assay; epg: Eggs per gram; FEC: Faecal egg count; FECRT: Faecal egg count reduction test; Fh: Fasciola hepatica; FhLiv: Clonal isolate of Fasciola hepatica; MLG: Multilocus genotype; NEJ: Newly excysted juvenile; PGP: P-glycoprotein; PM: Post-mortem; PP: Percentage positivity; T: Treated with $10 \mathrm{mg} / \mathrm{kg}$ triclabendazole 10 days prior to PM; TCBZ-: No treatment with $10 \mathrm{mg} / \mathrm{kg}$ triclabendazole; TCBZ: Triclabendazole; TCBZ+: Treatment with $10 \mathrm{mg} / \mathrm{kg}$ triclabendazole; TCBZ-R: Triclabendazole-resistant; TCBZ-S: Triclabendazole- susceptible; wpi: Weeks post-infection}

\footnotetext{
Acknowledgements

We would like to acknowledge the support of the Veterinary Investigation Centre, Carmarthen, Wales, UK and the Animal and Plant Health Agency, APHA. We also wish to extend our gratitude to the farmers who provided faecal samples from sheep. We are grateful for the assistance and expertise of Ridgeway Research Ltd and their staff, in particular Paula Martin and Oliver Gladstone. We would like to thank Ms Alice Balard, Grade 5 technician, for her assistance with maintenance of snail colonies.
} 


\section{Funding}

This research was funded by Biotechnology and Biological Sciences Research Council (BBSRC) BB/1002480/1 award and the European Union FP6 contract number 023025 - DELIVER (Design of Effective and sustainable control strategies for LIVER fluke in Europe). Neither funder was involved in the design of the study or collection, analysis, and interpretation of data.

\section{Availability of data and materials}

Data supporting the conclusions of this article are included within the article. Raw data are available from the corresponding author on request.

\section{Authors' contributions}

$J H, K C$ and DW made substantial contributions to conception and design and acquisition of data. $\mathrm{JH}, \mathrm{KC}, \mathrm{KA}, \mathrm{NB}, \mathrm{CH}$ and DW contributed to the analysis and interpretation of data. $\mathrm{JH}, \mathrm{KC}, \mathrm{NB}$ and $\mathrm{DW}$ were involved in drafting the manuscript and revising it critically for important intellectual content. All authors read and approved the final manuscript.

\section{Ethics approval and consent to participate}

The provision of faecal samples from sheep, by farmers, did not require consent as samples were sent to University of Liverpool for routine diagnostics. All applicable institutional, national and international guidelines for the care and use of animals were followed. Experimental infection in sheep was conducted under Home Office Licence PPL 40/3621 in accordance with Animal Scientific Procedures Act 1986 and ethical approval for the study was provided by the University of Liverpool Committee on Research Ethics.

\section{Consent for publication}

Not applicable.

\section{Competing interests}

The authors declare that they have no competing interests.

\section{Publisher's Note}

Springer Nature remains neutral with regard to jurisdictional claims in published maps and institutional affiliations.

\section{Author details}

${ }^{1}$ Veterinary Parasitology, Dept Infection Biology, Institute of Infection and Global Health, University of Liverpool, Liverpool L69 7ZJ, UK. ${ }^{2}$ School of Biological Sciences, Medical Biology Centre, Queen's University Belfast, Belfast BT9 7BL, UK

\section{Received: 22 March 2018 Accepted: 13 June 2018}

Published online: 26 June 2018

\section{References}

1. Pritchard GC, Forbes AB, Williams DJ, Salimi-Bejestani MR, Daniel RG. Emergence of fasciolosis in cattle in East Anglia. Vet Rec. 2005;157:578-82.

2. McCann CM, Baylis M, Williams DJ. Seroprevalence and spatial distribution of Fasciola hepatica-infected dairy herds in England and Wales. Vet Rec. 2010;166:612-7.

3. Fürst T, Keiser J, Utzinger J. Global burden of human food-borne trematodiasis: a systematic review and meta-analysis. Lancet Infect Dis. 2012;12:210-1

4. Fox NJ, White PC, McClean CJ, Marion G, Evans A, Hutchings MR. Predicting impacts of climate change on Fasciola hepatica risk. PLoS One. 2011:6:e16126.

5. Charlier J, Hostens M, Jacobs J, Van Ranst B, Duchateau L, Vercruysse J. Integrating fasciolosis control in the dry cow management: the effect of closantel treatment on milk production. PLoS One. 2012;7:e43216.

6. Boray JC, Crowfoot PD, Strong MB, Allison JR, Schellenbaum M, Vonorelli M. Treatment of immature and mature Fasciola hepatica infections in sheep with triclabendazole. Vet Rec. 1983;113:315-7.

7. Overend DJ, Bowen FL. Resistance of Fasciola hepatica to triclabendazole. Aust Vet J. 1995;72:275-6.

8. Fairweather I. Triclabendazole: new skills to unravel an old(ish) enigma. J Helminthol. 2005;79:227-34.

9. Brennan GP, Fairweather I, Trudgett A, Hoey E, McCoy MCM, et al. Understanding triclabendazole resistance. Exp Mol Pathol. 2007;82:104-9.
10. González LC, Esteban JG, Bargues MD, Valero MA, Ortiz P, Náquira C, MasComa S. Hyperendemic human fascioliasis in Andean valleys: an altitudinal transect analysis in children of Cajamarca Province. Acta Trop. 2011;120: $119-29$.

11. Kelley JM, Elliott TP, Beddoe T, Anderson G, Skuce P, Spithill TW. Current threat of triclabendazole resistance in Fasciola hepatica. Trends Parasitol. 2016:32:458-69.

12. Clark EL, Blake DP. Genetic mapping and coccidial parasites: past achievements and future prospects. J Biosci. 2012;37:879-86.

13. Protasio AV, Tsai IJ, Babbage A, Nichol S, Hunt M, Aslett MA, et al. A systematically improved high quality genome and transcriptome of the human blood fluke Schistosoma mansoni. PLoS Negl Trop Dis. 2012;6:e1455.

14. Valentim CL, Cioli D, Chevalier FD, Cao X, Taylor AB, Holloway SP, et al. Genetic and molecular basis of drug resistance and species-specific drug action in schistosome parasites. Science. 2013:342:1385-9.

15. Criscione CD, Valentim CL, Hirai H, LoVerde PT, Anderson TJ. Genomic linkage map of the human blood fluke Schistosoma mansoni. Genome Biol. 2009;10:R71

16. Cwiklinski K, Dalton JP, Dufresne PJ, La Course J, Williams DJ, Hodgkinson J, Paterson S. The Fasciola hepatica genome: gene duplication and polymorphism reveals adaptation to the host environment and the capacity for rapid evolution. Genome Biol. 2015;16:e71.

17. McConville M, Brennan GP, Flanagan A, Edgar HWJ, Hanna REB, McCoy M, et al. An evaluation of the efficacy of compound alpha and triclabendazole against two isolates of Fasciola hepatica. Vet Parasitol. 2009;162:75-88.

18. Walker SM, McKinstry B, Boray JC, Brennan GP, Trudgett A, Hoey EM, et al. Response of two isolates of Fasciola hepatica to treatment with triclabendazole in vivo and in vitro. Parasitol Res. 2004:94:427-38.

19. Fairweather I. Liver fluke isolates: a question of provenance. Vet Parasitol. $2011 \cdot 176: 1-8$

20. Hodgkinson J, Cwiklinski K, Beesley NJ, Paterson S, Williams DJL. Identification of putative markers of triclabendazole resistance by a genome-wide analysis of genetically recombinant Fasciola hepatica. Parasitology. 2013;140:1523-33.

21. George SD, Baker K, Lake L, Vanhoff K, D'Arcy R, Emery D, Rolfe PF Characterization of multiple life stages of two Australian Fasciola hepatica isolates in sheep. Vet Parasitol. 2017;248:4-9.

22. Doyle SR, Laing R, Bartley DJ, Britton C, Chaudhry U, Gilleard JS, et al. A genome resequencing-based genetic map reveals the recombination landscape of an outbred parasitic nematode in the presence of polyploidy and polyandry. Genome Biol Evol. 2018;10:396-409.

23. Cwiklinski K, Allen K, LaCourse J, Williams DJ, Paterson S, Hodgkinson JE. Characterisation of a novel panel of polymorphic microsatellite loci for the liver fluke, Fasciola hepatica, using a next generation sequencing approach. Infect Genet Evol. 2015:32:298-304.

24. Salimi-Bejestani MR, McGarry JW, Felstead S, Ortiz P, Akca A, Williams DJ. Development of an antibody-detection ELISA for Fasciola hepatica and its evaluation against a commercially available test. Res Vet Sci. 2005;78:177-81.

25. Beesley NJ, Williams DJL, Paterson S, Hodgkinson JE. Fasciola hepatica demonstrates high levels of genetic diversity, a lack of population structure and high gene flow, possible implications for drug resistance. Int J Parasitol. 2017:47:11-20.

26. Grevelding CG. Genomic instability in Schistosoma mansoni. Mol Biochem Parasitol. 1999;101:207-16.

27. Bayne CJ, Grevelding CG. Cloning of Schistosoma mansoni sporocysts in vitro and detection of genetic heterogeneity among individuals within clones. J Parasitol. 2003:89:1056-60.

28. Yin M, Hu W, Mo X, Wang S, Brindley PJ, McManus DP, Davis GM, Feng Z, Blair D. Multiple near-identical genotypes of Schistosoma japonicum can occur in snails and have implications for population-genetic analyses. Int $J$ Parasitol. 2008;38:1681-91.

29. Belfaiza M, Abrous M, Rondelaud D, Moncef M, Dreyfuss G. The use of tetraphyll as food for snails increases the intensity of cercarial shedding in Galba truncatula infected with Fasciola hepatica. Parasitol Res. 2004; 94:86-90

30. Rondelaud D, Mouzet R, Vignoles P, Dreyfuss G, Cabaret J. The production of mammalian trematode infective stages by the snail Galba truncatula. J Helminthol. 2014:88:105-11.

31. Dreyfuss G, Rondelaud D. Fasciola gigantica and F. hepatica: a comparative study of some characteristics of Fasciola infection in Lymnaea truncatula infected by either of the two trematodes. Vet Res. 1997;28:123-30. 
32. Dreyfuss G, Vignoles P, Rondelaud D, Vareille-Morel C. Fasciola hepatica: characteristics of infection in Lymnaea truncatula in relation to the number of miracidia at exposure. Exp Parasitol. 1999;92:19-23.

33. Dreyfuss $G$, Alarion $N$, Vignoles $P$, Rondelaud $D$. A retrospective study on the metacercarial production of Fasciola hepatica from experimentally infected Galba truncatula in central France. Parasitol Res. 2006;98:162-6.

34. Vignoles P, Favennec $L$, Rondelaud D, Dreyfuss $G$. The experimental production of Fasciola hepatica metacercariae from three aquatic populations of Galba truncatula. J Helminthol. 2003;77:275-7.

35. Hodasi JK. The output of cercariae of Fasciola hepatica by Lymnaea truncatula and the distribution of metacercariae on grass. Parasitology. 1972 64:53-60.

36. Crossland NO, Bennett MS, Cawdery MJ. Preliminary observations on the control of Fasciola hepatica with the molluscicide N-tritylmorphloine. Vet Rec. 1969:84:182-4.

37. Rondelaud D, Vignoles P, Dreyfuss G. Fasciola hepatica: the developmental patterns of redial generations in naturally infected Galba truncatula. Parasitol Res. 2004;94:183-7.

38. Rondelaud D, Vignoles P, Dreyfuss G. Larval trematode infections in Galba truncatula (Gastropoda, Lymnaeidae) from the Brenne Regional Natural Park, central France. J Helminthol. 2016;90:256-61.

39. Wilkes CP, Thompson FJ, Gardner MP, Paterson S, Viney ME. The effect of the host immune response on the parasitic nematode Strongyloides ratti. Parasitology. 2004;128:661-9.

40. Panaccio M, Trudgett A. Molecular biology. In: Dalton JP, editor. Fasciolosis. Oxon: CABI Publishing: 1999. p. 449-61.

41. Wilkinson R, Law CJ, Hoey EM, Fairweather I, Brennan GP, Trudgett A. An amino acid substitution in Fasciola hepatica P-glycoprotein from triclabendazole-resistant and triclabendazole-susceptible populations. Mol Biochem Parasitol. 2012;186:69-72.

42. Elliott TP, Spithill TW. The T687G SNP in a P-glycoprotein gene of Fasciola hepatica is not associated with resistance to triclabendazole in two resistant Australian populations. Mol Biochem Parasitol. 2014:198:45-7.

43. Gilleard JS. Haemonchus contortus as a paradigm and model to study anthelmintic drug resistance. Parasitology. 2013;140:1506-22.

44. Choi YJ, Bisset SA, Doyle SR, Hallsworth-Pepin K, Martin J, Grant WN, Mitreva M. Genomic introgression mapping of field-derived multiple-anthelmintic resistance in Teladorsagia circumcincta. PLoS Genet. 2017;13:e1006857.

45. Daniel R, van Dijk J, Jenkins T, Akca A, Mearns R, Williams DJLA. composite faecal egg count reduction test to detect resistance to triclabendazole in Fasciola hepatica. Vet Rec. 2012;171:153.

46. Wood IB, Amaral NK, Bairden K, Duncan JL, Kassai T, Malone JB, et al. World Association for the Advancement of Veterinary Parasitology (W.A.A.V.P.) second edition of guidelines for evaluating the efficacy of anthelmintics in ruminants (bovine, ovine, caprine). Vet Parasitol. 1995;58:181-213.

\section{Ready to submit your research? Choose BMC and benefit from:}

- fast, convenient online submission

- thorough peer review by experienced researchers in your field

- rapid publication on acceptance

- support for research data, including large and complex data types

- gold Open Access which fosters wider collaboration and increased citations - maximum visibility for your research: over $100 \mathrm{M}$ website views per year

At BMC, research is always in progress.

Learn more biomedcentral.com/submissions 